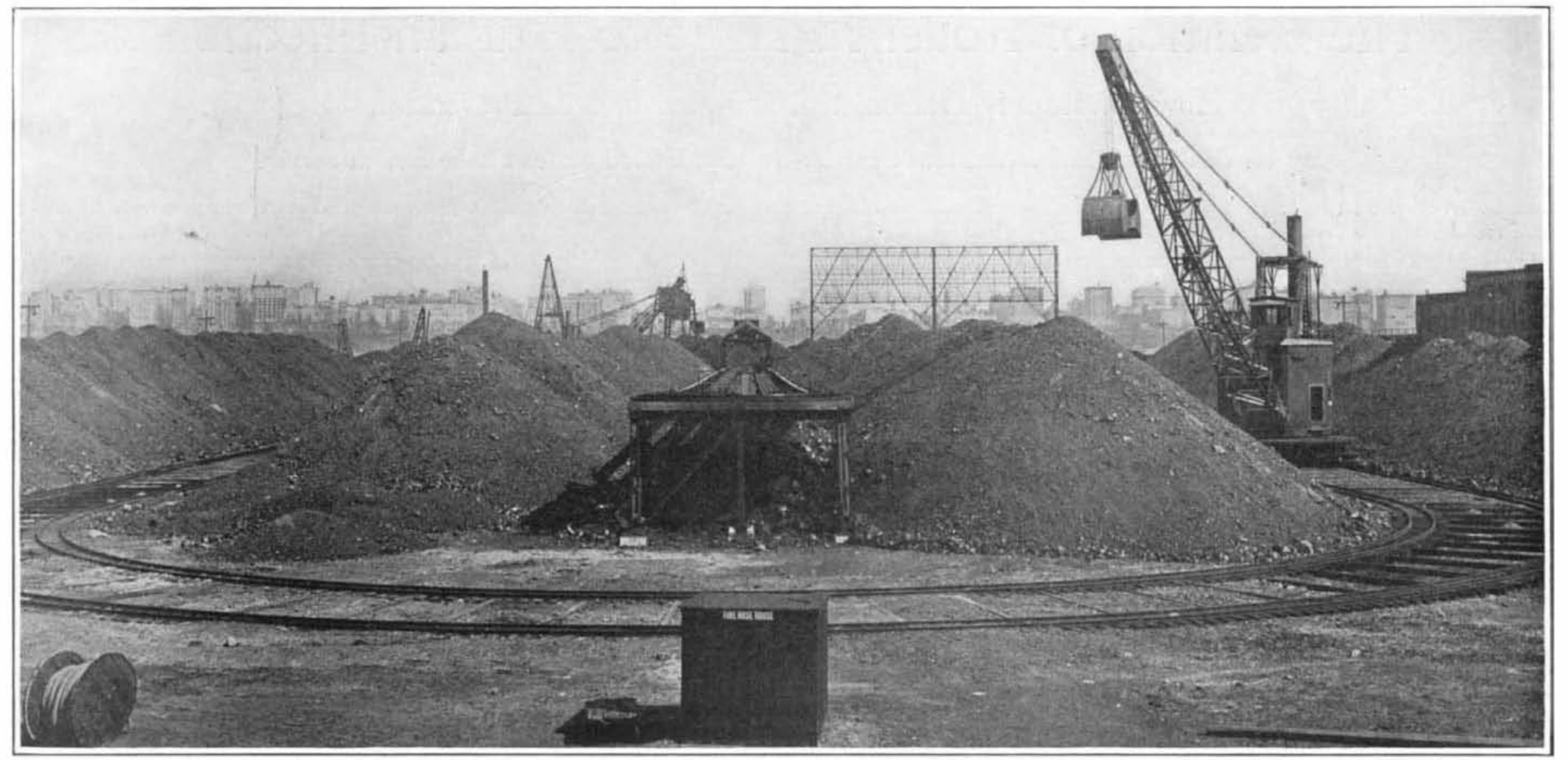

Coal storage piles, dumping tracks and locomotive crane in a surplus supply yard near New York.

\title{
The Fuel Supply of a Big Power Plant
}

\author{
Storage of Coal at New York
}

By J. F. Spinger

Just about all the coal that comes to New York must, prior to actual delivery or use, be transferred to barges or other vessels for a final short trip by water. The reason lies, of course, in the fact that the great metropolis is, with the exception of a single borough, disconnected from the mainland. And this borough is also practically separated because of the fact that it is on the east side of the Hudson, while the sources of coal lie on the west side.

New York city by itself consumes an enormous yearly tonnage. From its harbor coal is dispatched by boat to New England coast points, and there is a very large business concerned in furnishing bunker coal to vessels sail ing from or calling at this port. Counting the entire waterborne traffic, the harbor of New York is probably the second coal harbor of the world, its yearly business falling but little below that of Cardiff in South Wales. Every year, about $25,000,000$ tons of anthracite and bituminous coal are transferred from rail to vessel in the American harbor.

The big users of coal in the city are the electric light and power companies, together with the gas and local transportation companies. Among these is the New York Edison Company, which supplies all Manhattan south of 135th Street. This not very large area is probably the greatest user of electricty of its size in the entire world. To satisfy the demands of the $2,000,000$ poulation in this district, the company consumes about 600,000 tons of coal per year, or, say, 1,500 tons per day. The great generating station is at Waterside on the extreme east side of Manhattan, about two and one half miles north of the Battery. Coal is received from the railroads at terminal points on the New Jersey shore. Inevitably, there is a considerable water haul. But the physical necessities are increased by those which come from other sources.

It is absolutely essential to the company's operation that there shall be no reasonably avoidable interruptions to its service-especially interruptions due to failure in the coal supply. These may come from natural cause such as storms along the railroad lines, or from strike at mine or on road, or from accidents, and to avoid these incidents, the company seeks to maintain a reserve of something like a half-year's supply. This means a bi storage yard. Under present conditions of the development of coal storage it is very necessary to avoid considerable depths of coal in the storage piles and preferabl to avoid wide piles. The reason for this lies in the liability of the deep pile, and perhaps the broad pile, to spontaneous combustion. This is the thing that the big users of bituminous coal have to dread, but adequate precautions usually mean a widespread storage yard. It will readily be seen from the foregoing that a storage yard with a capacity of 200,000 or 300,000 tons would entail on the Manhattan waterfront an excessive real estate investment, so the electric company has its storage yard in New Jersey on the west bank of the Hudson, six or seven miles north of the Battery. The shortest route would lie across Manhattan, but distance is not always the controlling element in the cost of freight transportation. It is undoubtedly very much cheaper to make the longer trip by barge around the southern tip of Manhattan Island than to use both barge and truck on the shorter route.

The storage yard at Shadyside was originally estab- between rails. Going, the cable and track run north along the dock, then west, then south, then west to a circular turn at the far end of the extension. Returning, the cable and track continue on, coming east on the extension, and then circles around the river front storage space, returning to the starting point from the south.

The cars, which carry two or three tons each, are operated automatically and dump their loads on both sides by doors hinged half way up the body of the car and extending its full length. They are mechanically connected to open and close together. Inside, the bottom
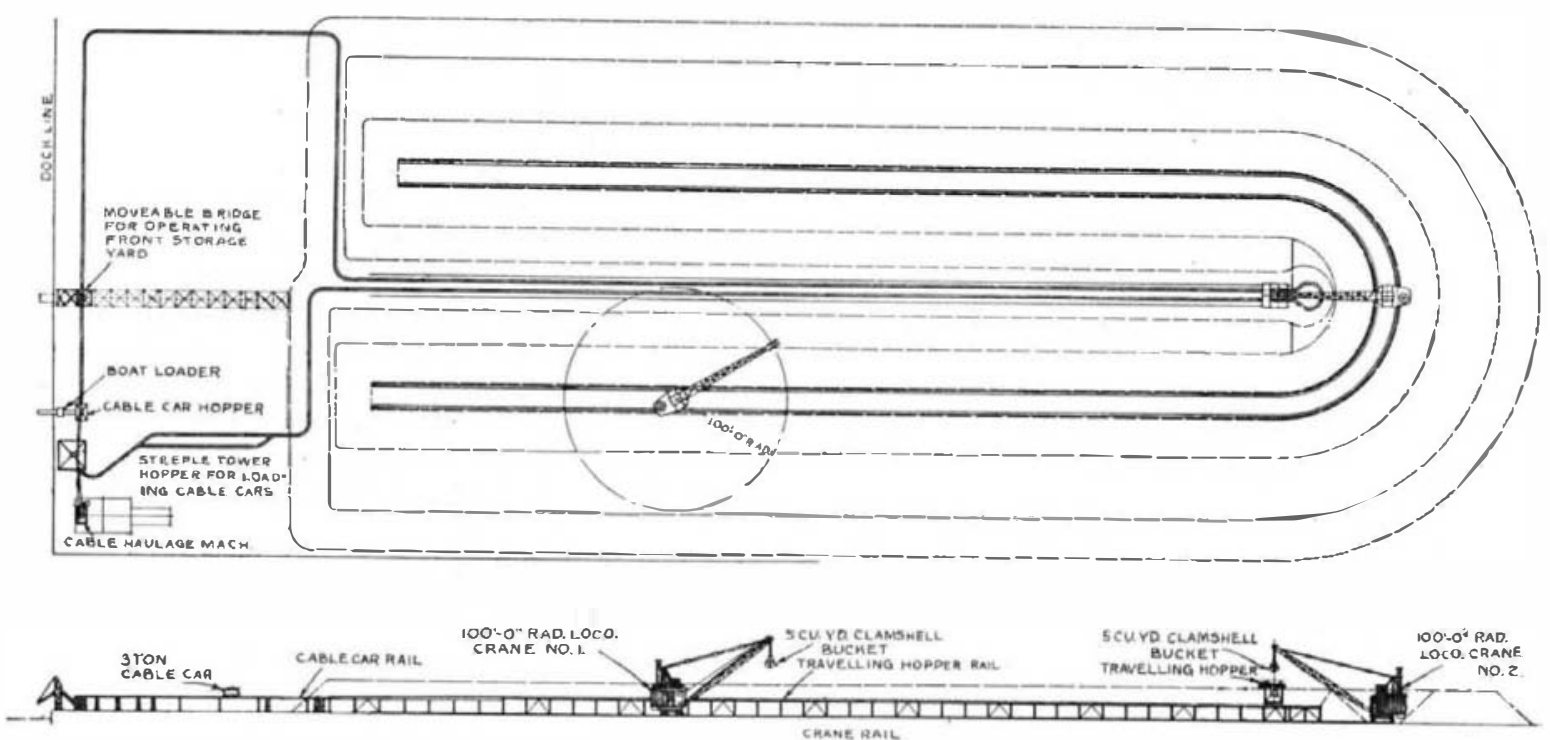

Plan of the Shadyside storage yard and tracks.

lished as an anthracite plant, but is now used for bituminous coal exclusively. Here the coal is brought to the dock, which parallels the river bank, by barge and then stored in the open. The yard may be conveniently described as consisting of two parts. One is rectangular and on the waterfront, the longer sides paralleling the river. The rear part of the yard consists of a more extensive piece of ground on which are four long and parallel piles at right angles to the river.

An automatic tramway encircles the rectangular portion facing the river, and has a long double-track extension at the rear that runs between the two central piles of the rear storage. Two of the rear piles parallel the extension on each side.

The tramway is an elevated railroad operated by an endless cable, which runs on tdle rollers or wheels set of the car consists of a longitudinal ridge. A cross-secion of the car would disclose a pretty good letter $\mathrm{W}$. The doors are ordinarily tripped automatically by means of a detachable block secured to the tramway structure.

The cars are provided with a suitable grip for the purpose of frictionally engaging the cable. The rip is Det and and these operations require the attention of an attendant.

The function of the tramway is to furnish transportation between the front of the dock and that portion of the rear storage space that lies beneath the elevated tracks of the tramway extension. The storage piles are more or less removed horizontally from this narrow strip, consequently additional means are required to make the necessary transfers. These are effected by two big locomotive cranes which operate upon a continu. 


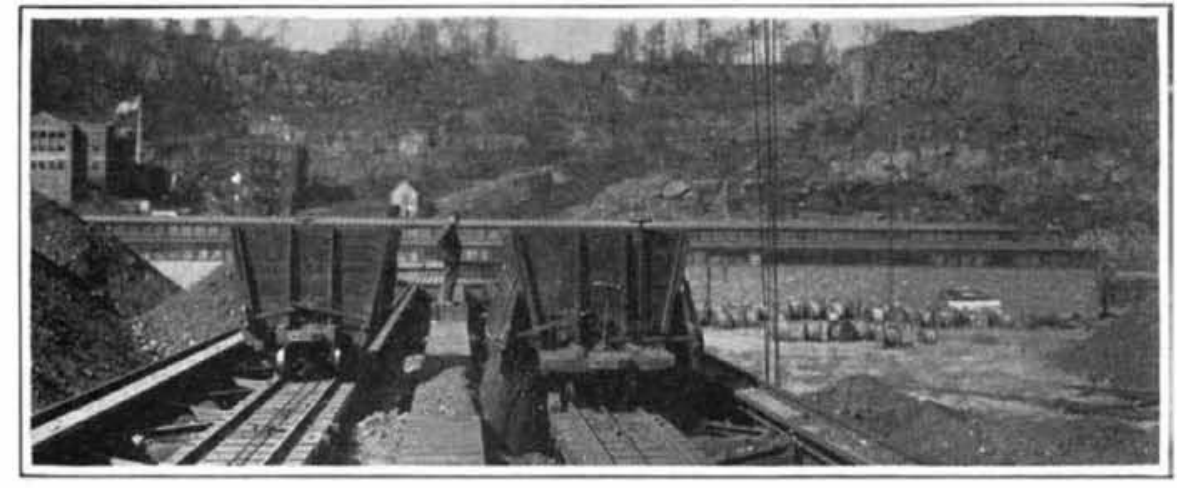

Cableway car automatically dumping its load.

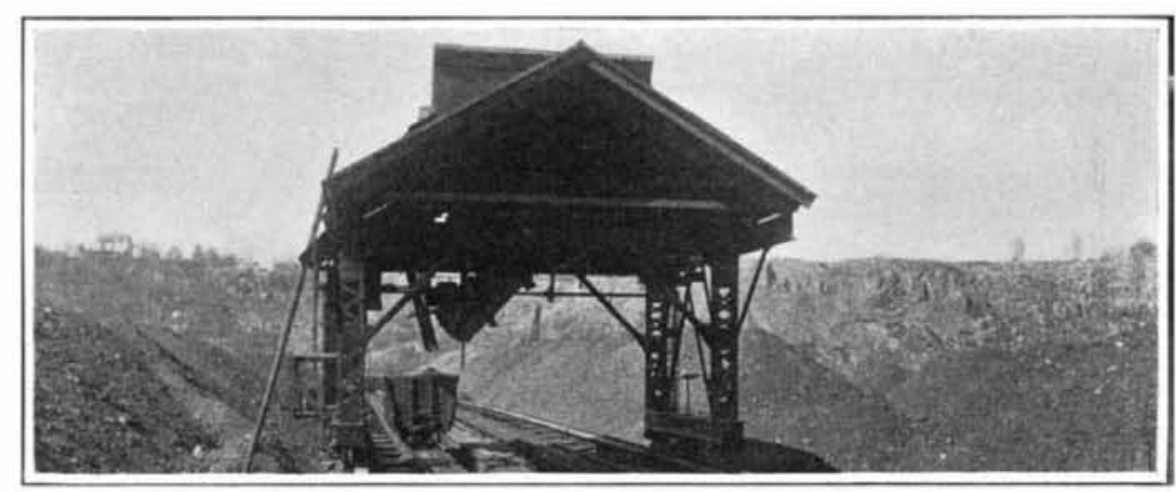

Movable loading-out hopper over cableway tracks. ous single track, which extends between the outer and inner piles on either side, and across their ends.

These two cranes have booms about 100 feet long, from which points clam-shell buckets operate to pick up the coal from alongside the tramway and store it in long piles, one on either side of the crane track; or they can take coal from the piles and transfer it to the tram cars for re-shipment to the station in New York.

The front part of the storage yard is served by a movable bridge, which may be shifted up and down the dock. This bridge has an extension reaching out over the water, and the actual handling of coal is done by a clamshell bucket whose movable point of support is a suitable carriage or trolley.

At the storage yard there are two operations: one concerned with receiving coal-loading-in; and the other with discharging coal to barges-loading-out.

In loading-in, the loaded barge from the railway terminal several miles to the south is brought up alongside the dock and secured in position. The bridge extension of the hoisting tower is dropped, and the coal is hoisted out of the barge by the clam-shell bucket, which either dumps its load into a hopper over the tramway track, or is traversed along the bridge and deposits its load in the front storage space. An expert operator of the bucket will ordinarily manage the lifting and traversing more or less simultaneously. The bucket will then begin to pass in as it rises in the air. Similarly, in getting the load from the barge, it will usually be the case that the bucket can be started on its drop while on the way out to the barge.

The empty car, as it comes along the dock from the south, will be boarded by a workman, who loosens the grip and halts the car beneath the hopper. It requires but a moment to fill the car, when it will be ready to be dispatched. The operation of seizing the ever-moving cable must, however, not be performed until the workman notes by the position of the car next ahead that the proper interval between cars has been attained. He the proper interval between cars has been attained. He
secures the grip and steps off, ready to take care of the next empty from the south.

The loaded car goes on without attendance, following the line around the curves to the back storage yard. When it reaches a point on the extension, whether on the west-going track or on the east-coming track, where the dumping block has been secured temporarily, the doors will be tripped, both falling open simultaneously, and the coal will be promptly discharged. The car does not stop-there is no need--but continues on its way back to the dock front

One of the big locomotive cranes standing on its track near the point where the tram car discharges its load scoops up the coal and drops it upon one of the piles on either side of its track as desired, the long boom being swung around as necessary. When loading-out the coal is recovered from the four rear storage piles by the two cranes, or from the dock storage by a clam-shell bucket running back and forth on the bridge. In the former case the assistance of the tramway is employed. In order to facilitate loading the tram cars on the tram. way extension, a special movable loading hopper is used. This is mounted on a framework which straddles both tram tracks, and operates back and forth on its own track. While the hopper will be used to discharge over the return tram track, it may be reached by the locomotive cranes from either side of the tramway extension. The tram cars are halted beneath the hopper one by one and loaded for the trip to the dock front. Arrived alongside the dock and barge, the car will discharge into a loading device which receives the coal, and then by means of its conveyor deposits it on board the barge.

Spontaneous combustion is, as already stated, the great enemy to be feared in such plants as that at Shadyside, where the coal is piled pretty high-up to 35 feet, and trouble from fire is experienced here, presumably from this cause. It may surprise those unfamiliar with questions relating to the storage of coal to learn that water is not considered a proper agent with which to fight fires arising from spontaneous combustion. Such fires are apt to be rather deep seated, and the coal above and around the fire will likely be more or less converted into colie, with the result that a protective covering is
created. Probably if unlimited quantities of water could be employed the fire could be readily put out with it. Digging the fire out of its nest is one effective method. This is what is done at Shadysille.

Danger from fire might, however, occur from other

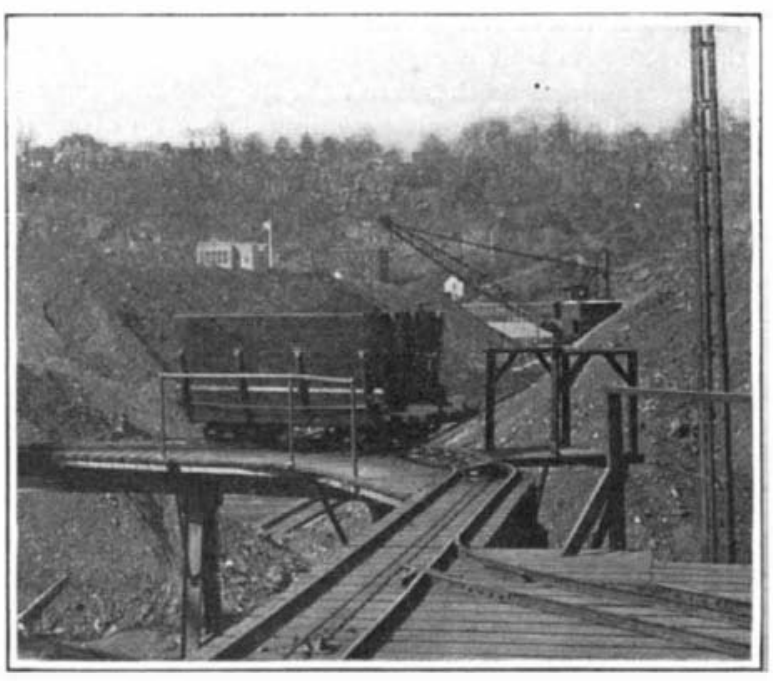

Loaded car on way to rear yard.

sources, especially in a plant like that at Shadyside, where provision has to be made for night operation. Crossed wires, broken insulation and the like might ver readily combine with other conditions and precipitate much trouble. To light the storage piles and take care

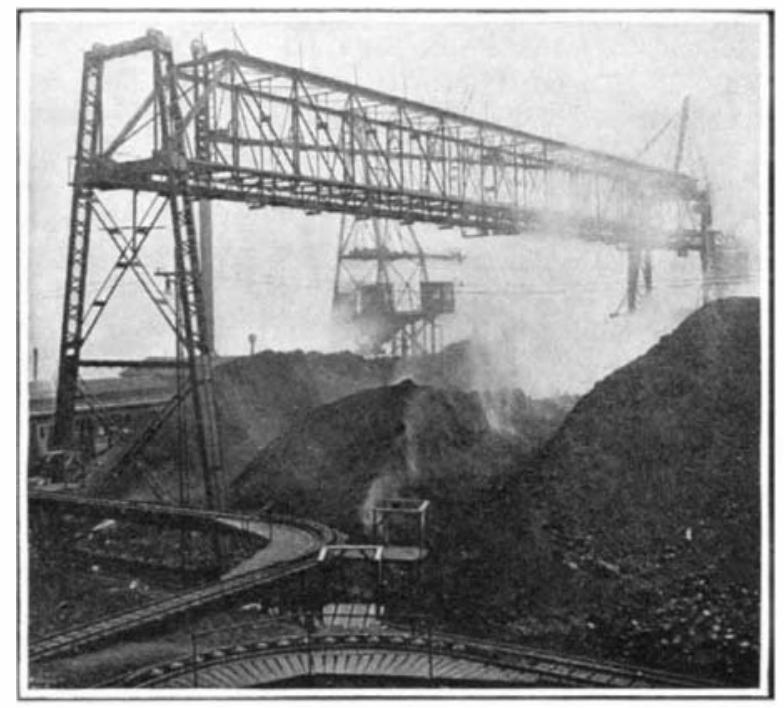

Movable transfer bridge in front yard.

of fire risk constituted a real problem. To provide powe and light for the big locomotive cranes was a further one To avoid interference with the free operation of the crane booms 1,000 candle-power inclosed electric light have been installed on 40 -foot posts set on the outside lines.

\section{Battlefield Casualties}

In the figures for the total British losses since the beginning of the war, recently given out by the War Office, the proportion of killed to wounded works out almost exactly in the ratio of one dead for each three wounded. This was for all the forces in all zones and classes of military activity. No differentiation for the casualties in trench warfare has as yet been given out officially, but certain reports indicate that in such warfare about one person is killed to each two wounded. These figures are interesting in comparison with the proportion of $1: 4$ which had been accepted before the war, and indicates that the kind of warfare which is being conducted bears directly on the amount and character of transportation and hospital facllities required in the zone of such warfare. Our accepted basis for estimates on the clearance of the battlefield will, like so many other standards, doubtless have to undergo material modification.--From the Military Surgeon.

\section{Uarregpandente}

['T'he editors are not responsible for statements made in the correspondence column. Anonymous communications cannot be considered, but the names of correspondents will be withheld when so desired.]

\section{Gravitation at the Earth's Center}

To the Editor of the SCIENTIFIC AMERICAN SLPPLEMENT: In the article in the SoIEntific AMERICAN SuppleMENT of February 19th (No. 2094) by Mr. John Candee Dean it is stated that "the pressure of gravitation near the earth's center amounts to millions of pounds to the square inch, and there matter is reduced to the density of platinum."

In using the term "near the earth's center," does Mr. Dean mean to convey the impression that, so far as the earth is concerned, the force of gravity is greatest at the earth's center and that such force becomes less as the surface is approached?

Or does he mean to imply that the force of gravitation exerted near the center is greater than at the center itself? If the latter, where is the point of greatest force, and how is the result calculated? Minneapolis: F. L. Moffett.

To the above question Mr. Dean sends the following reply :

To the Editor of the Scientific American Supplement In reply to Mr. Moffett's questions, I would say that the force of gravitation is greatest at the surface of the earth and zero at its center. In my article on the Mysteries of Matter I say: "The pressure of gravitation near the earth's center amounts to millions of pounds to the square inch, and matter there is reduced to the density of platinum. Under this force liquids yield like a sponge. Owing to the enormous pressure that gravitation imposes on the earth it is compacted into a dense mass as rigid as a ball made from nickel steel armor plate."

We have penetrated but a short distance into the earth's outer crust, and therefore have no absolute knowledge of the condition of matter at the center of the earth. We do know, however, that so far as we have penetrated, the temperature increases and the gravitational force decreases as we go down. We know that the average density of the earth's crust is about three times that of water, while the mean density of the whole earth is 5.53 times that of water. From this it is obvious that the density of matter at the earth's center must be eight or ten times that of water. Prof. A. J. J. See, the celebrated astronomer of the United States Naval Observatory at Mare Island, estimates the density at the earth's center to be equal to that of platinum.

The temperature of the earth appears to increase from the outer surface downward at the rate of one degree Fahrenheit for every 50 or 60 feet, and at the relatively short distance of a very few miles the temperature must be very high. If we disregard the effect of pressure, matter below a certain point would be fused; farther below, matter would be in a gaseous state; still farther down all matter would be at a critical temperature, where there would be no chemica action, and it would be resolved into its simple elements, or in a monatomic condition.

The melting point, however, increases with the pressure. Geologists formerly supposed that the earth was in a molten condition, except the outer crust, but now it is believed to be solid throughout, except possibly for small molten pockets, near the surface. Since the melting point increases with the pressure, and the enormous mass pressing toward the center increases the pressure relatively faster than the increase of temperature, the earth remains a solid body from surface to center. John Canpee Dran. 